\title{
Regional differences in the impact of science and technology investment on China's economic development
}

\author{
Wang Yuwei \\ Beijing Jiaotong University, Beijing, China \\ 17120552@bjtu.edu.cn
}

Keywords: Science and technology investment, Regional Differences, Economic development.

\begin{abstract}
Difference in the basic conditions and the level of development lead to different impacts of science and technology investment. This paper uses the panel data of China's 30 provincial administrative regions from 2008 to 2016 to conduct the empirical test about the regional differences in the impact of science and technology investment on economic development. The results show that there are great differences between different provinces in different regions of China. The positive impact of financial science and technology investment on economic development is obvious in the western region than in the eastern and central regions, and the $R \& D$ personnel input promotes economic development more in the eastern region than in the central and western regions, while the R\&D expenditure effect has only shown positive effects in some regions. Based on these results and causes, it is necessary to improve the allocation management mechanism of financial technology investment, optimize the R\&D expenditure structure, and improve the scientific and technological talent resource management system.
\end{abstract}

\section{Introduction}

Science and technology investment is the core element of economic development, and investment science and technology is the prerequisite for technological progress. Since the reform and opening, China has been insisting the basic development guidelines that science and technology are the primary productive forces, which greatly promoted China's economic development. Due to the serious division of China's sector and the large differences in the basic conditions and level of economic development in various regions, it is highly probable to be different in the effects of scientific and technological inputs on economic development between different regions. Therefore, this study aims to explore the existence of this difference and the possible path to achieve a rational allocation of resources for science and technology.

\section{Literature references}

The relationship between technology investment and economic development has always been the focus of the theoretical community. As early as the 1930s, the technological progress parameters were derived from the production functions of Cobb and Douglas[1]. In 1957, Solow[2] derived the growth rate equation, revealing that technological advancement promoted the development of economy. In the 1980s, economists represented by Romer and Lu-cas proposed the theory of endogenous economic growth. These studies above provide important reference and theoretical basis for subsequent related researches.

In recent years, most research results show that China's science and technology investment has a positive role in promoting economic development. For example, Hu Enhua et al. [3] found that technology investment can promote economic growth in the current and lag periods. Yin Linsen's[4] study indicated that technological investment and activities have significant effect on industrial economic growth. While a few scholars drew different conclusions, such as Fang Wei et al. [5] found that the correlation between the density of technological talent resources and regional economic development is not significant. Xue Junbo et al. [6] found that the contribution of technological human resources in some provinces to economic growth is small or even negative. From the 
perspective of regional differences, Hu Zhenhua et al. [7] found a significant gap in the scale of science and technology investment between regions and provinces in China. The study of Zhang Qianrong[8] showed that the efficiency of science and technology input in developed regions are significantly higher than in other regions.

In summary, the role of science and technology investment in promoting economic growth is generally recognized in theory, but the perspective of regional differences needs to be further studied. Meanwhile there are few studies on the control variables in terms of research content, and not many research methods based on variable coefficient models. This paper analyzes the relationship between science and technology input and economic growth by using provincial investment and macroeconomic data, and carries out regional classification to summarize the regional characteristics of the relationship between China's science and technology investment and economic growth.

\section{Equations and Data Sources}

This paper cites the Cobb-Douglas production function to examine the impact of technology investment on economic development, specifically incorporating the input factors of science and technology into the traditional formula. The model is:

$$
\mathrm{Y}=A K^{\alpha} L^{\beta} S^{\theta}
$$

Where $\mathrm{Y}$ is the total output, $\mathrm{K}$ is capital investment, $\mathrm{L}$ is labor input, $\mathrm{S}$ is the input factor of science and technology and A denotes other factors that affect economic development in addition to capital and labor factors. Convert the function to logarithmic form:

$$
\ln Y=\ln A+\alpha \ln K+\beta \ln L+\theta \ln S
$$

This paper selects indicators of financial technology investment, R\&D expenditure and R\&D personnel input as the input factors of science and technology, and establish a basic panel data model:

$$
\operatorname{lnGDP}_{i t}=c_{i t}+\alpha_{i} \operatorname{lnFix}{ }_{i t}+\beta_{i t} \operatorname{lnLab}_{i t}+\theta_{1 i} \operatorname{lnFis}_{i t}+\theta_{2 i} \operatorname{lnRde}_{i t}+\theta_{3 i} \operatorname{lnRdp}_{i t}+\mu_{i t}
$$

Where $\mathrm{i}$ is the individual of the section, $\mathrm{t}$ is the time, $\mathrm{c}$ is the intercept and $\mu$ is the random error term.

This paper uses GDP to measure the degree of economic development, fixed assets investment to measure capital investment(Fix), and uses the total indicators of urban units, private enterprises and individual employment to measure labor input(Lab). In addition, financial technology expenditures, internal expenditures for $R \& D$ funds, and full-time equivalents of $R \& D$ personnel are used respectively to measure financial technology investment(Fis), $R \& D$ expenditure(Rde), and $R \& D$ personnel input (Rdp). $\alpha, \beta, \theta_{1}, \theta_{2}, \theta_{3}$ are elasticity of these variables.

Due to the availability of data from 2008 to 2016, this paper selects 30 provincial-level administrative regions in China as research samples. The data are all from China Statistical Yearbook (2009-2017) and China Science and Technology Statistical Yearbook (2009-2017). Corresponding processing has been done to eliminate the impact of price level changes. The descriptive statistical analysis results of the six variable data are shown in Table 1.

Table 1 Descriptive statistical analysis of variables

\begin{tabular}{ccccc}
\hline variable & mean & max. & min. & std. dev. \\
\hline LNFIS & 5.195 & 5.676 & 4.557 & 0.382 \\
\hline LNFIX & 8.622 & 8.919 & 8.217 & 0.223 \\
\hline LNGDP & 9.731 & 10.110 & 9.282 & 0.274 \\
\hline LNLAB & 6.987 & 7.298 & 6.584 & 0.218 \\
\hline LNRDE & 6.860 & 7.247 & 6.295 & 0.292 \\
\hline LNRDP & 12.312 & 12.442 & 12.152 & 0.113 \\
\hline
\end{tabular}




\section{Empirical analysis}

\subsection{Unit root test}

This paper uses LLC test, IPS test, Fisher-ADF test, Fisher-PP test and other methods to perform unit root test on each research variable data. The test results show that the original sequence has unit roots, and the first-order difference of the sequence is stable. The test results are shown in Table 2.

Table 2 Panel unit root test result

\begin{tabular}{cccc}
\hline variable & \multicolumn{3}{c}{ Testing method } \\
\cline { 2 - 4 } & LLC test & Fisher-ADF test & Fisher-PP test \\
\hline$\Delta$ LNGDP & $-3.95002^{* * *}$ & 54.7369 & $153.010^{* * *}$ \\
\hline$\Delta$ LNFIX & $-10.7992^{* * *}$ & $148.541^{* * *}$ & $212.160^{* * *}$ \\
\hline$\Delta$ LNFIS & $-5.66942^{* * *}$ & 74.7806 & $124.355^{* * *}$ \\
\hline$\Delta$ LNLAB & $-4.65907^{* * *}$ & 61.9316 & $233.716^{* * *}$ \\
\hline$\Delta$ LNRDE & $-14.0182^{* * *}$ & $198.466^{* * *}$ & $308.302^{* * *}$ \\
\hline$\Delta$ LNRDP & $-6.09768^{* * *}$ & $80.6466^{*}$ & $99.2332^{* * *}$ \\
\hline
\end{tabular}

Note: $* * *, * *$, and $*$ represent the significance levels of $1 \%, 5 \%$, and $10 \%$ respectively. Tables 4 and 6 are the same.

\subsection{Cointegration test}

The single integer order is 1 , indicating that there may be a long-term cointegration relationship between variables. Then the cointegration test is carried out by Eviews9.0. As Table 3 shows, there indeed be a long-term stable relationship between the six variables. Another cointegration test is performed on the residual of the regression; the $\mathrm{P}$ value of the ADF is 0.00 . Therefore, the null hypothesis is rejected, and the residual is considered to be stable, so there is a cointegration relationship between the variables.

Table 3 Panel data cointegration test results

\begin{tabular}{cccc}
\hline Testing method & Test statistics & Test statistic value & P value \\
\hline Pedroni test & Panel v-Statistic & -7.096834 & 1.0000 \\
& Panel rho-Statistic & 5.307445 & 1.0000 \\
\cline { 2 - 4 } & Panel PP-Statistic & -43.09846 & 0.0000 \\
\cline { 2 - 4 } & Group rho-Statistic & 7.966488 & 1.0000 \\
\cline { 2 - 4 } & Group PP-Statistic & -50.25772 & 0.0000 \\
\hline Kao test & ADF & -14.78480 & 0.0000 \\
\hline
\end{tabular}

\subsection{Model estimation}

The fixed effect model was determined by Hausman test, and the variable coefficient model was established by $\mathrm{F}$ test. In order to facilitate the comparative analysis of the regional differences, this paper divides the 30 provincial-level administrative regions into three regions based on the statistical caliber of the National Bureau of Statistics, respectively being the eastern, central and western regions. The eastern region includes Beijing, Tianjin, Hebei, Liaoning, Shanghai, Jiangsu, Zhejiang, Fujian, Shandong, Guangdong and Hainan, the central region includes Shanxi, Jilin, Anhui, Jiangxi, Heilongjiang, Henan, Hubei and Hunan, and the western region includes Inner Mongolia, Chongqing, Sichuan, Guizhou, Yunnan, Gansu, Qinghai, Ningxia, Guangxi, Shanxi and Xinjiang. The results are shown in Tables 4, 5 and 6.

The results of the effect of science and technology input on economic development in the eastern region are shown in Table 4. The intercept term is an important reflection of the basic effects. The higher the intercept, the stronger the basic effect, on the contrary, the lower the intercept, the weaker the basic effect. The average intercept in the eastern region is calculated to be 3.96, with the highest being 8.86 in Beijing and the lowest in Tianjin at 0.43. The R\&D personnel's investment has played a significant role in promoting the economic development of Shanghai, Fujian and Guangdong, but had no positive effect on Shandong, indicating that the resources of Shandong for scientific and technological talents is insufficient. The effects of R\&D expenditure and financial science and technology investment on the economic development of the eastern region are not significant. 
Specifically, Shanghai, Liaoning and Hainan have shown positive effect of R\&D expenditure, while financial technology investment has a tendency to restrain. This may be due to the unreasonable allocation of financial technology, which brings competition to high-efficiency innovation activities, and restrain technological progress. Conversely, R\&D expenditure may have a depressing effect in Jiangsu, Shandong and Tianjin, while financial technology investment has a positive impact, indicating that financial guidance is more important in these regions.

Table 4 Variable Coefficient Model Estimation Results of Eastern Region

\begin{tabular}{|c|c|c|c|c|c|c|c|c|c|c|c|}
\hline \multirow[t]{2}{*}{ Prov. } & \multirow[t]{2}{*}{ intercept } & \multicolumn{2}{|c|}{$\operatorname{lnrdp}$} & \multicolumn{2}{|c|}{ lnrde } & \multicolumn{2}{|c|}{$\operatorname{lnfix}$} & \multicolumn{2}{|c|}{$\operatorname{lnfis}$} & \multicolumn{2}{|c|}{ lnlab } \\
\hline & & COEF. & $\mathrm{T}$ & COEF & $\mathrm{T}$ & COEF & $\mathrm{T}$ & COEF & $\mathrm{T}$ & COEF & $\mathrm{T}$ \\
\hline BJ & 8.86 & 0.93 & 1.61 & 0.05 & 0.25 & 0.07 & 0.16 & 0.04 & 0.14 & 0.62 & $\begin{array}{c}2.59 \\
* *\end{array}$ \\
\hline TJ & 0.43 & 0.38 & 0.83 & $\begin{array}{l}-0.09 \\
\end{array}$ & $\begin{array}{l}-0.27 \\
\end{array}$ & 0.16 & 0.64 & 0.19 & 0.34 & 0.35 & 0.48 \\
\hline $\mathrm{HE}$ & 2.18 & 1.26 & 1.56 & 0.06 & 0.49 & -0.34 & $\begin{array}{l}-0.79 \\
\end{array}$ & 0.17 & 0.75 & $\begin{array}{l}-0.32 \\
\end{array}$ & $\begin{array}{l}-0.83 \\
\end{array}$ \\
\hline $\mathrm{LN}$ & 6.31 & 0.96 & 1.42 & 0.18 & 1.10 & 0.89 & $\begin{array}{c}2.64 \\
* *\end{array}$ & -0.27 & -0.71 & -0.68 & -0.85 \\
\hline $\mathrm{SH}$ & 5.03 & 0.76 & $\begin{array}{c}3.29 \\
* * *\end{array}$ & 0.36 & 1.48 & 0.05 & 0.15 & -0.02 & -0.11 & -0.08 & -0.23 \\
\hline JS & 4.59 & 0.09 & 0.05 & -0.01 & $\begin{array}{c}-0.01 \\
\end{array}$ & 0.11 & 0.34 & 0.42 & 0.31 & 0.01 & 0.01 \\
\hline ZJ & 4.84 & 0.54 & 1.04 & 0.05 & 0.25 & -0.61 & -1.04 & 0.70 & 1.29 & 0.29 & 0.57 \\
\hline FJ & 1.45 & 0.33 & $\begin{array}{c}1.76 \\
*\end{array}$ & -0.03 & -0.27 & 0.48 & 0.95 & -0.23 & -0.28 & 0.34 & 0.80 \\
\hline SD & 5.31 & -0.27 & -0.47 & -0.14 & -1.15 & 0.38 & $\begin{array}{c}1.72 \\
*\end{array}$ & 0.45 & 1.21 & 0.28 & 0.66 \\
\hline GD & 3.86 & 0.45 & $\begin{array}{c}2.30 \\
* *\end{array}$ & -0.18 & -1.10 & 0.46 & 1.59 & -0.05 & -0.43 & 0.30 & 1.57 \\
\hline $\mathrm{HI}$ & 0.69 & 0.39 & 0.98 & 0.15 & 0.86 & 0.31 & 1.35 & -0.21 & -0.66 & 0.25 & 0.86 \\
\hline
\end{tabular}

Note: $1 .{ }^{* *},{ }^{* *}$, and * represent the significance levels of $1 \%, 5 \%$, and $10 \%$ respectively. Tables 4 and 6 are the same.

2. Due to the limit of Table space, The province name was processed based on "Announcement on China Internet Domain Name System”. Tables 4 and 6 are the same. Correspondences are as follows: Beijing-BJ, Tianjin-TJ, Hebei-HE, Liaoning-LN, Shanghai-SH, Jiangsu-JS, Zhejiang-ZJ, Fujian-FJ, Shandong-SD, Guangdong-GD, Hainan-HI.

The results of the effect of science and technology input on economic development in the central region are shown in Table 5. The average intercept of the central region was 3.69, with the higher ones being Shanxi at 11.27 and Henan at 12.49, and the lowest being Anhui at 0.46 . The province where the financial science and technology investment is effective is Heilongjiang, for every $1 \%$ increase in input, GDP will increase by $0.6 \%$. The R\&D expenditure had a significant effect on the economic development in Jiangxi and Jilin, specifically there is a positive effect in Jilin, while a significant lag effect on economic development in Jiangxi. Meanwhile, the results shows that R\&D personnel have played a significant positive role in the economic development of Shanxi, Jilin and Hubei. Among them, Shanxi has the largest promotion effect (for every 1\% increase in R\&D personnel investment, GDP will increase by $1.4 \%$ ).

Table 5 Variable Coefficient Model Estimation Results of Central Region

\begin{tabular}{|c|c|c|c|c|c|c|c|c|c|c|c|}
\hline \multirow[t]{2}{*}{ Prov. } & \multirow{2}{*}{$\begin{array}{c}\text { interce } \\
\text { pt }\end{array}$} & \multicolumn{2}{|c|}{ lnrdp } & \multicolumn{2}{|c|}{ lnrde } & \multicolumn{2}{|c|}{$\operatorname{lnfix}$} & \multicolumn{2}{|c|}{$\operatorname{lnfis}$} & \multicolumn{2}{|c|}{ lnlab } \\
\hline & & COEF & $\mathrm{T}$ & COEF & $\mathrm{T}$ & COEF & $\mathrm{T}$ & COEF & $\mathrm{T}$ & COEF & $\mathrm{T}$ \\
\hline SX & 11.27 & 1.40 & $\begin{array}{l}3.07 \\
* * *\end{array}$ & -0.04 & -0.27 & 0.57 & $\begin{array}{l}2.75 \\
* * *\end{array}$ & 0.01 & 0.12 & -0.18 & -0.34 \\
\hline $\mathrm{JL}$ & 6.35 & 0.68 & $\begin{array}{c}2.23 \\
* *\end{array}$ & 0.18 & $1.76^{*}$ & 0.27 & 1.33 & -0.11 & -0.54 & 0.60 & 1.96 \\
\hline HL & 6.88 & -0.16 & -0.47 & -0.30 & -0.73 & 0.29 & 0.89 & 0.60 & $\begin{array}{l}2.64 \\
* * *\end{array}$ & -0.06 & -0.14 \\
\hline $\mathrm{AH}$ & 0.46 & 0.48 & 0.98 & -0.05 & -0.44 & 0.01 & 0.01 & 0.20 & 0.42 & 0.21 & 0.42 \\
\hline JX & 1.19 & -0.17 & -0.25 & -0.78 & $\begin{array}{c}-2.04 \\
* *\end{array}$ & 0.80 & $\begin{array}{l}3.10 \\
* * *\end{array}$ & -0.04 & -0.21 & 1.09 & $\begin{array}{l}2.80 \\
* * *\end{array}$ \\
\hline HA & 12.49 & -0.91 & -0.63 & -0.27 & -0.76 & 0.30 & 1.14 & 1.07 & 1.04 & 0.15 & 0.58 \\
\hline HB & 4.41 & 1.06 & $\begin{array}{c}1.77 \\
*\end{array}$ & 0.12 & 0.72 & -0.02 & -0.06 & 0.22 & 1.21 & -0.15 & -0.37 \\
\hline $\mathrm{HN}$ & 1.41 & 0.40 & 1.09 & 0.08 & 0.51 & -0.15 & -0.38 & 0.78 & 1.25 & 0.05 & 0.34 \\
\hline
\end{tabular}

Note: Shanxi-SX, Jilin-JL, Heilongjiang-HL, Anhui-AH, Jiangxi-JX, Henan-HA, Hubei-HB, Hunan-HN.

The results of the effect of science and technology input on economic development in the western region are shown in Table 6 . The average intercept of the western region is 2.80 , the highest of which is Chongqing, at 10.68, and the lowest is Inner Mongolia at 0.57. The financial science and 
technology investment has played a significant positive role in the economic development of Guangxi, Chongqing, Sichuan and Xinjiang, among which Sichuan has the most promoting effect. The R\&D expenditure did not show a significant positive effect on economic development, and except for Chongqing, it has a negative impact, indicating that R\&D expenditure has a significant lag effect on the economic development of the western region. The economic development effects of R\&D personnel on Sichuan, Yunnan, Tibet, Shaanxi and Qinghai are more significant and positive.

Table 6 Variable Coefficient Model Estimation Results of Western Region

\begin{tabular}{|c|c|c|c|c|c|c|c|c|c|c|c|}
\hline \multirow{2}{*}{$\begin{array}{l}\text { Pro } \\
\text { v. }\end{array}$} & \multirow{2}{*}{$\begin{array}{c}\text { interce } \\
\mathrm{pt}\end{array}$} & \multicolumn{2}{|c|}{ lnrdp } & \multicolumn{2}{|c|}{ lnrde } & \multicolumn{2}{|c|}{ lnfix } & \multicolumn{2}{|c|}{ lnfis } & \multicolumn{2}{|c|}{ lnlab } \\
\hline & & COEF & $\mathrm{T}$ & COEF & $\mathrm{T}$ & COEF & $\mathrm{T}$ & COEF & $\mathrm{T}$ & COEF & $\mathrm{T}$ \\
\hline NM & 0.14 & 0.57 & 1.06 & -0.02 & -0.18 & 0.10 & 0.52 & 0.32 & 1.28 & 0.01 & 0.03 \\
\hline GX & 4.85 & 0.67 & $\begin{array}{c}1.89 \\
*\end{array}$ & -0.03 & -0.30 & 0.01 & 0.05 & 0.21 & $\begin{array}{c}1.75 \\
*\end{array}$ & 0.74 & 1.52 \\
\hline CQ & 10.68 & -1.12 & -0.73 & 0.02 & 0.11 & 0.56 & $\begin{array}{c}2.21 \\
* *\end{array}$ & 0.63 & $\begin{array}{c}1.69 \\
*\end{array}$ & 0.29 & 0.53 \\
\hline SC & 8.57 & -0.11 & -0.22 & -0.05 & -0.42 & 0.10 & 0.46 & 0.80 & $\begin{array}{c}2.57 \\
* *\end{array}$ & -0.39 & $\begin{array}{c}-2.04 \\
* *\end{array}$ \\
\hline GZ & 2.10 & 0.11 & 0.20 & -0.17 & -1.09 & 0.57 & 1.55 & 0.20 & 0.54 & -0.15 & -0.26 \\
\hline YN & 4.74 & 0.83 & 1.15 & -0.10 & -0.94 & -0.04 & -0.14 & 0.39 & 1.11 & 0.49 & 1.08 \\
\hline $\mathrm{SN}$ & 0.54 & 0.15 & 0.20 & -0.21 & -1.27 & 0.75 & $\begin{array}{c}2.17 \\
* *\end{array}$ & -0.16 & -0.48 & 0.23 & 0.72 \\
\hline GS & 5.04 & 0.87 & $\begin{array}{c}1.72 \\
*\end{array}$ & -0.04 & -0.36 & 0.55 & $\begin{array}{l}4.07 \\
* * *\end{array}$ & -0.15 & -0.73 & -0.14 & -0.38 \\
\hline $\mathrm{QH}$ & 1.75 & 0.10 & 0.70 & -0.09 & -0.89 & 0.74 & $\begin{array}{l}3.35 \\
* * * \\
\end{array}$ & -0.11 & -0.93 & -0.38 & -0.45 \\
\hline NX & 2.72 & 0.70 & $\begin{array}{c}2.10 \\
* *\end{array}$ & -0.04 & -0.38 & 0.43 & $\begin{array}{l}3.00 \\
* * * \\
\end{array}$ & 0.12 & 0.67 & -0.19 & -0.70 \\
\hline $\mathrm{XJ}$ & 8.69 & -0.21 & -0.47 & -0.53 & -1.04 & 0.87 & 1.06 & 0.68 & $\begin{array}{l}2.65 \\
* * * \\
\end{array}$ & -1.19 & -1.04 \\
\hline
\end{tabular}

Note:Inner Mongoria-NM, Guangxi-GX, Chongqing-CQ, Sichuan-SC, Guizhou-GZ, Yunnan-YN, Shaanxi-SN, Gansu-GS, Qinghai-QH, Ningxia-NX, Xinjiang-XJ.

\section{Summary and Policy Suggestion}

The above results show that there is a long-term stable cointegration relationship between China's capital investment, labor and technology input and gross domestic product. The science and technology inputs in the eastern, central, and western regions have different basic effects on economic development. On average, the eastern region has the highest level and the western region has the lowest. The effects in different regions are quite different. The positive impact of financial technology investment in the western region on economic development is more obvious than that in the eastern and central regions. The $R \& D$ investment has played a positive role in some provinces in different regions, while there is no positive impact in some provinces, which depends on the availability of scientific and technological talent resources. The positive effect of R\&D personnel input on economic development in the eastern region is more obvious than that in the central and western regions, and among them, Shanghai gets the largest and significant positive effect. Based on the conclusions above, this paper proposes the policy recommendations as follows:

Firstly, improve the allocation management mechanism for fiscal science and technology investment, and ensure and promote the economic development effectiveness of science and technology investment. In terms of the allocation of national financial science and technology investment, it is important to focus on areas where financial technology investment is insufficient, while for provinces with little or no effect, measures should be formulated to optimize the input structure, focusing on technological innovation projects that promote industrial upgrading.

Second, adjust and optimize the R\&D funding structure. At present, China's R\&D funding structure is unreasonable, and there are more expenditure for experimental research, while relatively less funds are used for basic research and applied research. This requires adjustment and optimization 
of the R\&D expenditure input structure, which enhances the competitiveness of the industrial chain and continuously enhance the regional science and technology innovation stamina.

Third, improve the scientific and technological talent resource management system. The research results above show that some provinces in China have no sufficient scientific and technological human resources reserves represented by $R \& D$ personnel, which has inhibited the positive impact of technology investment on the economy. Therefore, it is necessary to improve the management of scientific and technological talents, and realize the standardized management of China's scientific and technological talents.

\section{References}

[1] Cobb C W and Douglas P H, A theory of production. American Economic Review, no.1, pp. 139-165. 1928.

[2] Solow R M. Technical change and the aggregate production. Review of Economics and Statistics, no.3, pp.312-320. 1957

[3] Yin Linsen, Hu Wenwei and LI Zhan, Research on Correlation between S\&T Input Industrial Economic Growth in Shanghai, China Soft Science, no.11, pp. 57-63, 2007.

[4] Hu Enhua, Liu Hong and Zhang Long, An empirical analysis of economic effect of China's science and technology investment, Science Research Management, vol.27, no.4, pp. 71-75+60, 2006.

[5] Fang Wei, Han Botang and Wang Dong, A study on the correlation of scientific and technological human resources with The development of regional economy, Science Research Management, vol.28, no.S1, pp. 132-136, 2007.

[6] Hu Zhenhua, Liu Duchi, Performance Evaluation of Scientific Research Inputup on Promoting Regional Economic Growth in China-Performance Evaluation Based on Hysteresis, China Soft Science, no.8, pp. 94-100, 2009.

[7] Zhang Qianrong, Empirical Study of Relative Efficiency of Regional S\&T Input Based on DEA Model, Journal of Dalian University of Technology(Social Sciences), vol.30, no.1, pp. 75-78, 2009.

[8] Xue Junbo, Zhou Zhitian and Yang Duogui, Empirical Research on the Contribution to Regional Economic Growth of the Technological Human Resources: An Analysis Based on the Province Scale, Technology Economics, vol.29, no.7, pp. 31-35, 2010. 